\title{
Normal and dwell fatigue behavior of a near-alpha titanium alloy - IMI 834
}

K.U. Yazar ${ }^{1}$, Anish Karmakar ${ }^{1}$, Vivek Sahu ${ }^{2}$, Amit Bhattacharjee ${ }^{3}$, Satyam Suwas ${ }^{1 *}$

${ }^{1}$ Department of Materials Engineering, Indian Institute of Science, Bangalore 560012, India

${ }^{3}$ Defence Metallurgical Research Laboratory, Hyderabad 500066, India

Author to whom all correspondence should be addressed:

*satyamsuwas@iisc.ac.in; +91-80-22933408

\section{Abstract}

Dwell sensitivity of titanium alloys at ambient temperature $\left(\sim 25^{0} \mathrm{C}\right)$ is a well-known phenomenon, although the question about the exact micromechanical reasons responsible for this still remains open. In this work, the normal and dwell fatigue response of a near-alpha titanium alloy, IMI 834, is studied. Samples with three different microstructures, namely, fully lamellar, fully 
equiaxed and bimodal, are evaluated for their dwell fatigue behaviors. A reduction in fatigue life by at least an order of magnitude is seen in all the three microstructures. Large plastic strain accumulation (almost equal to the monotonic ductility) was observed during the dwell fatigue loading condition and this is held responsible for this large debit in fatigue life. The normal fatigue lives decreased in the order, bimodal $>$ fully equiaxed $>$ fully lamellar, while the dwell fatigue lives decreased in the order, fully equiaxed $>$ fully lamellar $>$ bimodal. Bimodal microstructure showed a dwell fatigue debit of 17 , while fully lamellar and fully equiaxed showed a debit of 9 and 10 , respectively.

Keywords: Titanium alloy, IMI 834, Dwell fatigue.

\section{Introduction}

Near alpha and alpha-beta titanium alloys are extensively used in the aerospace industry due to their excellent specific strength and creep-fatigue properties. But these alloys are susceptible to a rather unusual phenomenon called dwell fatigue [1-3]. It is interesting that this phenomenon is most active at temperatures below $120^{\circ} \mathrm{C}$ and vanishes at about $200^{\circ} \mathrm{C}$ the reasons for which are not very clear [4]. The propensity of alpha titanium to undergo low-temperature creep is the primary reason for this phenomenon [5]. It is known that the crack initiation rather than the propagation life is affected by the dwell period [1]. As a result, detailed investigation of the fracture surfaces formed under dwell fatigue loading has been carried out in the past [6]. Subsurface and multiple crack initiation is the characteristic of dwell fatigue failures [7]. The stress redistribution arising at a 'soft-hard' grain interface and the resulting crack nucleation was studied by Hasija et al. [8] and Dunne et al. [9] using crystal plasticity modelling. Their predictions were also consistent with the experimental observations made by Sinha et al. [10] which was based on quantitative tilt fractography. The presence of microtextured zones (macrozones) are presumed to aggravate the issue and this fact has percolated throughout the dwell fatigue literature [11].

IMI 834 is a near alpha alloy that is used in the low-pressure compressor sections of a gas turbine engine. The rotating components of the gas turbine engine experience loading spectrums similar to that of dwell fatigue and this material is known to show dwell fatigue sensitivity in its normally used bimodal microstructure [12]. A dedicated study comparing the ambient temperature dwell fatigue behavior of different microstructures in IMI 834 is absent in the literature and hence is the focus of the current study. In this study, fatigue and dwell fatigue response of near alpha titanium alloy IMI 834 are evaluated. The motive of 
the present study is to investigate the effect of initial microstructure on the dwell fatigue behavior. Three different microstructures, namely. a fully lamellar, a fully equiaxed and a bimodal microstructure was chosen for the study.

\section{Materials and Methods}

\section{$\underline{\text { Starting material }}$}

The material used in the current study is a near $\alpha$ titanium alloy that was received as a gift from Defense Metallurgical Research Laboratory, Hyderabad, India in the form of rods of $26 \mathrm{~mm}$ diameter. This alloy had a composition of Ti-5.8Al-4Sn-3.5Zr$0.5 \mathrm{Mo} 0.7 \mathrm{Nb}-0.35 \mathrm{Si}-0.06 \mathrm{C}$ similar to that of IMI 834. The readers are referred to Chandravanshi et al. [13] for its detailed thermomechanical processing history.

\section{Mechanical Testing}

Ambient temperature $\left(\sim 25^{\circ} \mathrm{C}\right)$ tensile tests were performed at a strain rate of $10^{-3}$ on an Instron 5967 machine. Engineering stress-controlled fatigue and dwell fatigue tests as per ASTM 466 standard were performed on a BISS Nano plug and play machine. Schematic of the loading spectrum used for normal and dwell fatigue is given in Fig. 1. The maximum load used in both tests were fixed at 1.02 of proof stress. A stress ratio $(\mathrm{R})$ of 0.1 was used in all the tests.

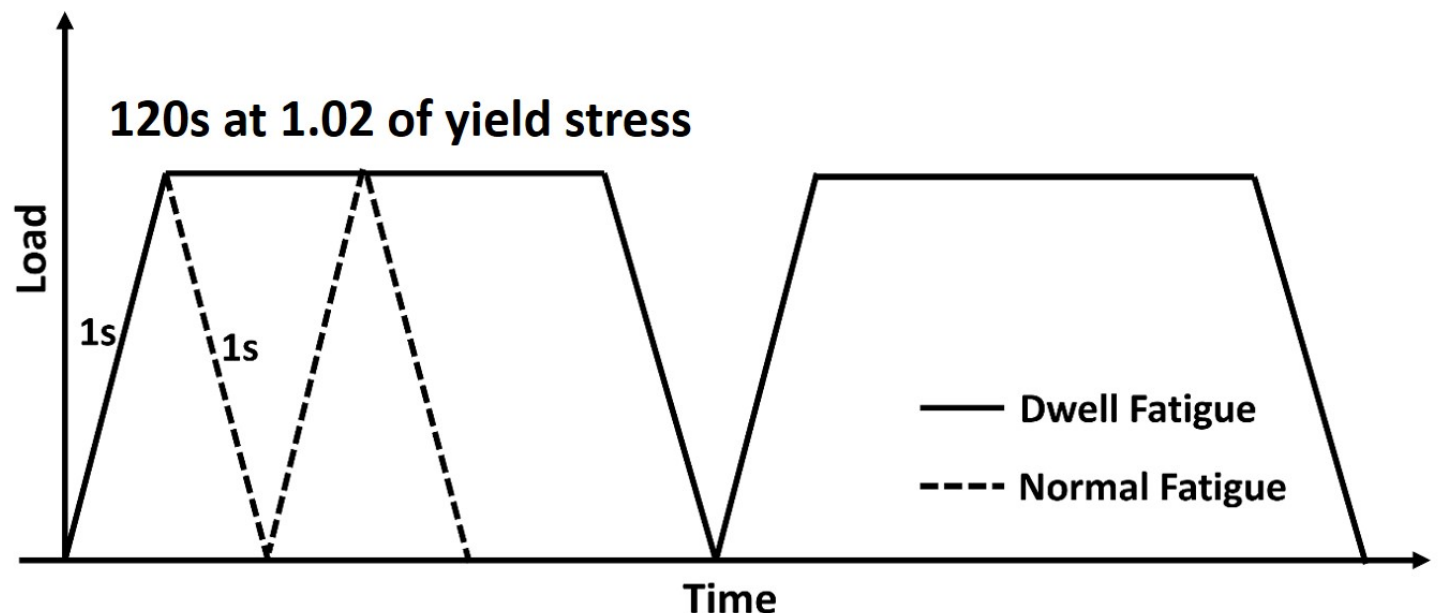

Fig. 1. Loading cycle used in fatigue and dwell fatigue testing 


\section{Microstructural characterization}

Microstructural characterisation was performed using scanning electron microscopy (SEM, ESEM Quanta). Electron back scattered diffraction (EBSD) was done using Helios NanoLab Dual-Beam, FEI, equipped with EDAX Digiview camera. Samples for SEM and EBSD were prepared using standard metallographic techniques, with the final polishing performed using colloidal silica. EBSD was done at an accelerating voltage of $25 \mathrm{kV}$ and a beam current of $6.5 \mathrm{nA}$ at a working distance of $11 \mathrm{~mm}$ and a stage tilt of $70^{\circ}$. Post processing was done using TSL OIM ${ }^{\mathrm{TM}}$ Analysis software.

\section{Results and discussion}

\section{$\underline{\text { Starting material }}$}

Back Scattered Electron micrograph of the starting material obtained from two orthogonal planes are shown in Fig. 2. It is characterized by the dark appearing alpha phase and bright appearing beta phase. Elongated primary alpha and lamellar secondary alpha grains are present in a matrix of beta phase. The volume fraction of beta phase is about $18 \%$. Of the alpha phase present, volume fraction of primary alpha is about $50 \%$ and the remaining is secondary alpha. EBSD was performed on the rod axis (RA) - transverse direction (TD) plane and the inverse pole figure map with respect to the normal direction is shown in Fig. 3. It can be seen that the microstructure is very heterogeneous in nature with clusters of grains with similar orientations present randomly in the sample. These clusters are termed as macrozones and is highlighted in Fig. 3a and an enlarged view of this region with crystal overlays is shown in Fig. 3b. It can be seen that grains with c-axis parallel to the loading axis and grains with c-axis nearly perpendicular to the loading axis are present as alternating layers. Such grain combinations were termed as rogue grain combinations by Dunne et al. [12] and is known to cause early crack nucleation under dwell fatigue loading conditions. 


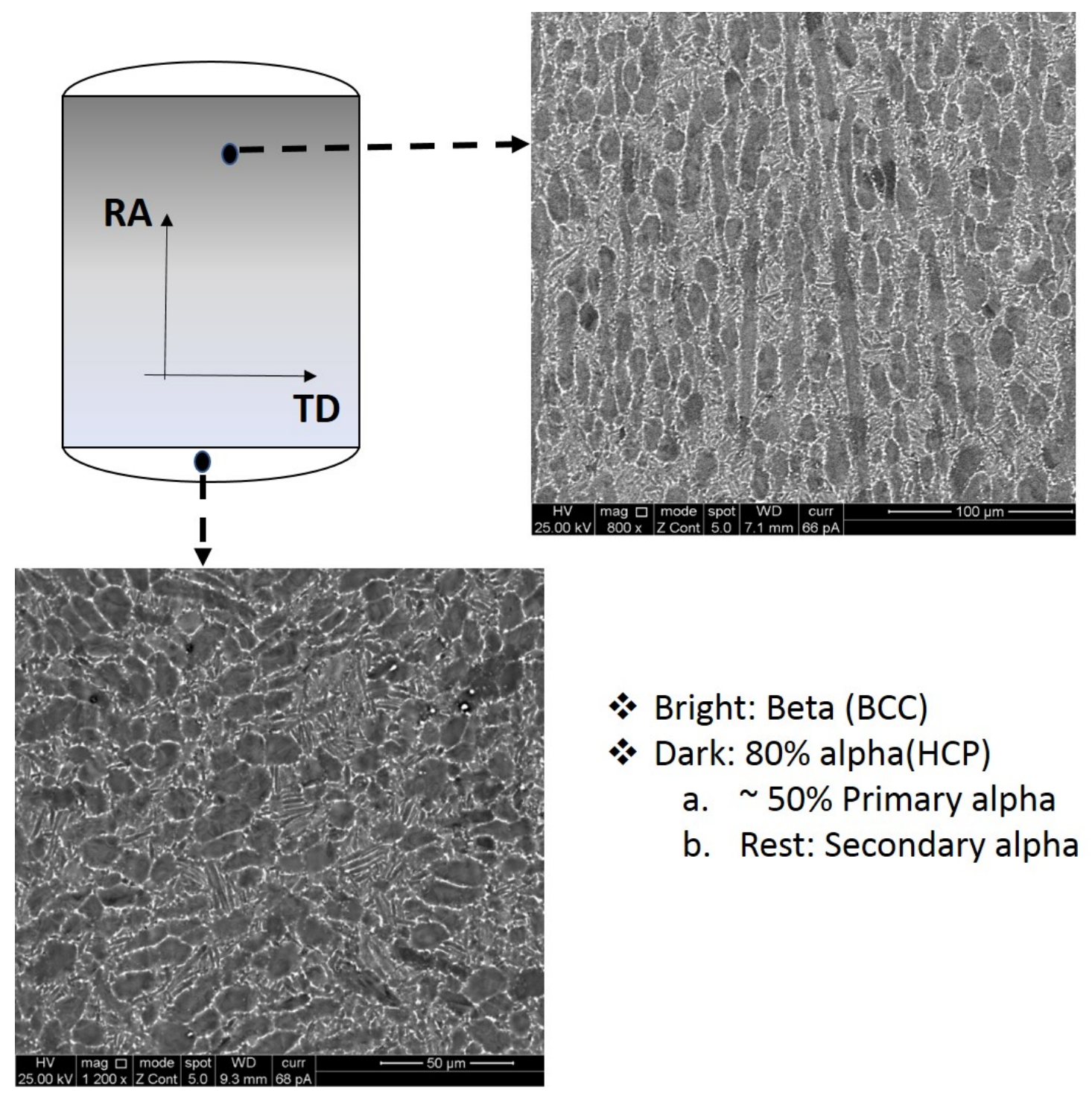

Fig. 2 BSE micrographs of the starting material

$\underline{\text { Heat treatment schedules and resulting microstructures }}$ 
The as-received rods were subjected to three different heat treatments as shown schematically in Fig. 3, which are conventionally used in near alpha and alpha-beta titanium alloys. The first type involves a beta annealing step followed by air cooling. The second heat treatment involves annealing in the alpha-beta phase field followed by air cooling. This step is followed by an ageing treatment at $700^{\circ} \mathrm{C}$ followed by air cooling. The third one is the same as that of the second, but the cooling rate from alpha-beta phase field is kept at $1^{\circ} \mathrm{C} / \mathrm{min}$. The microstructure resulting from the three different heat treatments is shown in Fig. 4 in the same order as that of the heat treatments shown in Fig. 4. These are well-known microstructures in near alpha alloys like IMI 834 . The microstructural characteristics of these three microstructures are summarized in Table. 1. Tensile and fatigue samples were extracted from the heat-treated rods along their axial direction and the loading axis coincides with the rod axis.

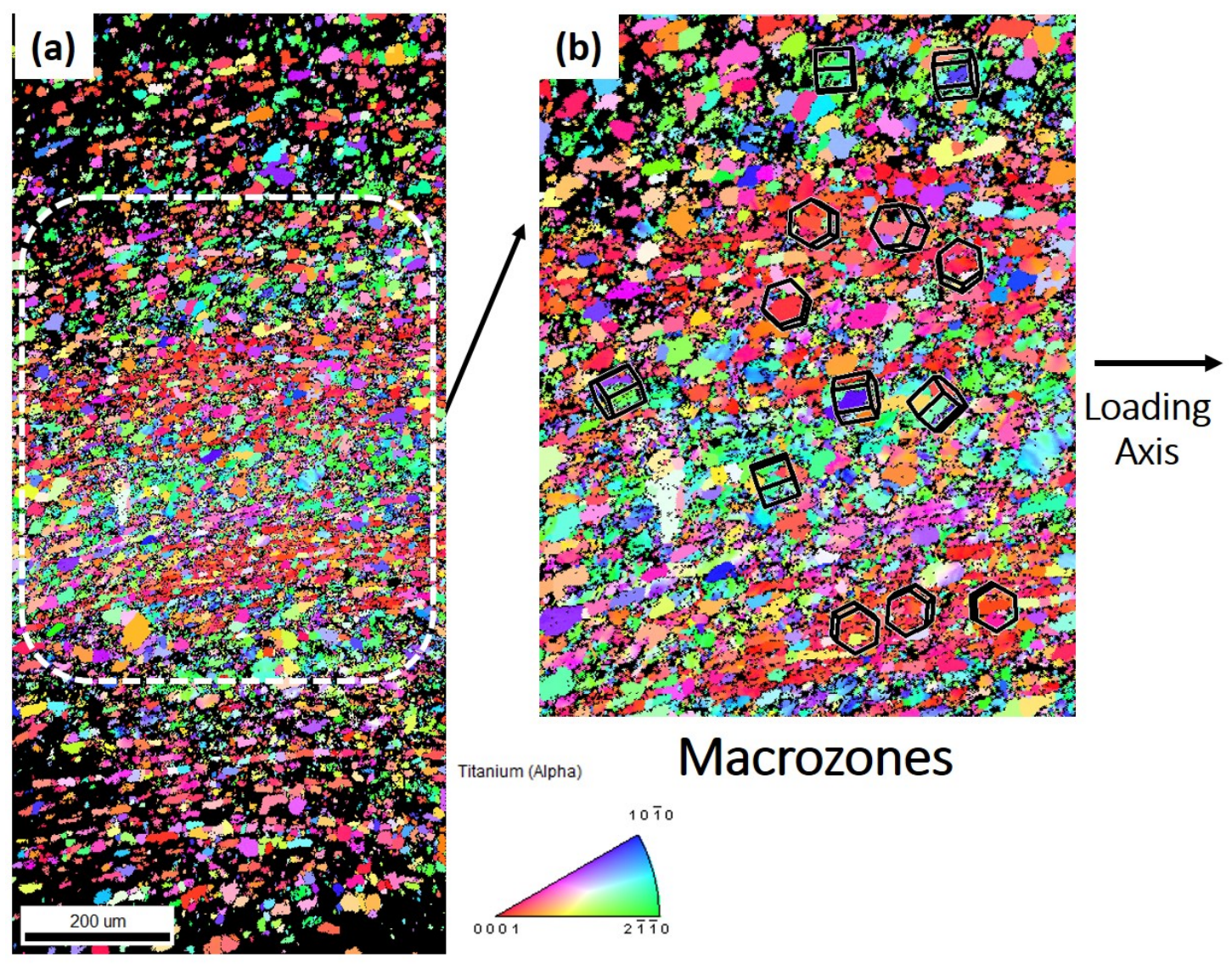

Fig. 3 (a) Normal direction_IPF map of the starting material taken on the transverse face (b) macrozones in the starting material. 
(a)

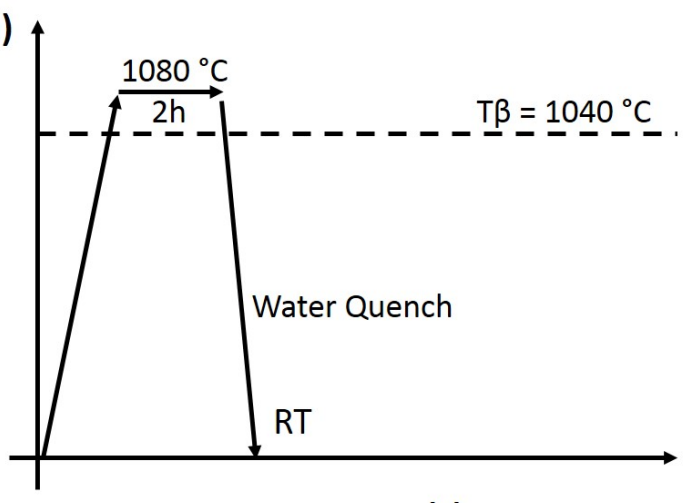

(b)

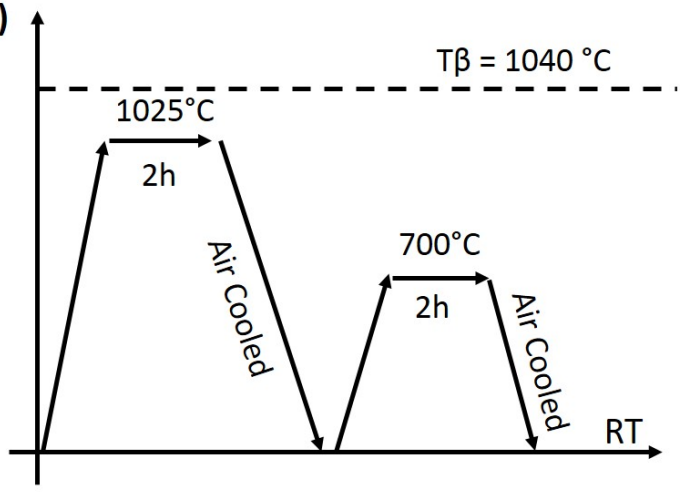

(c)

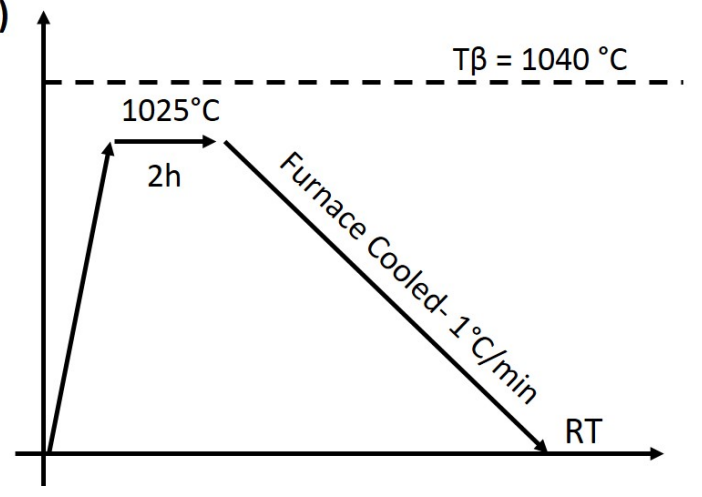

Fig. 4 Heat treatment schedule employed for obtaining (a) fully lamellar (b) bimodal and (c) fully equiaxed microstructures. 

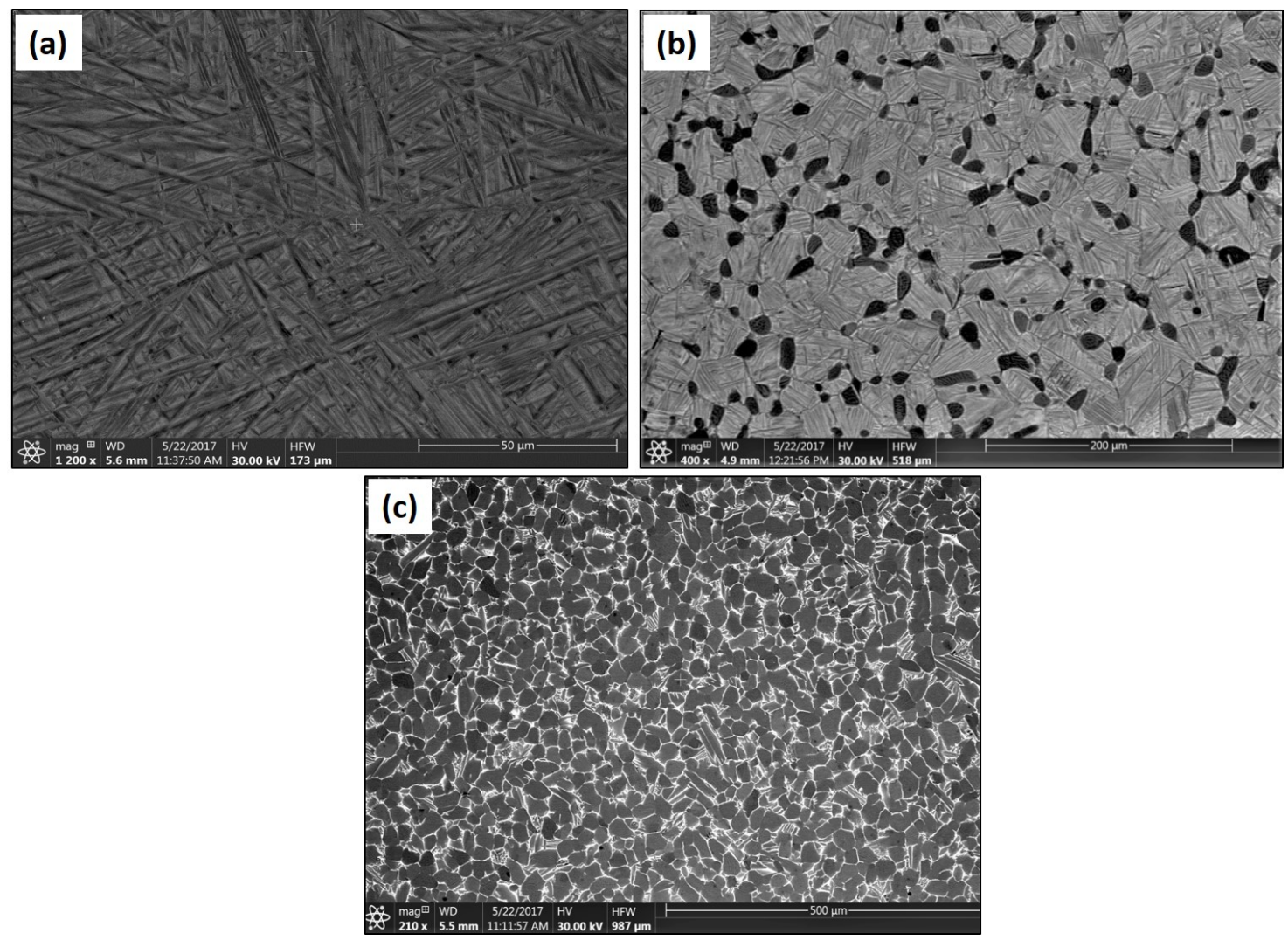

Fig. 5 Microstructures obtained after heat treatments (a) fully lamellar (b) bimodal and (c) fully equiaxed.

Table 1 Important microstructural features

\begin{tabular}{|c|c|c|c|}
\hline & FL & BM & FE \\
\hline Vol. fr. of primary alpha & NA & $21-24 \%$ & $>80 \%$ \\
\hline Size of primary alpha & NA & $14 \pm 3 \mu \mathrm{m}$ & $41 \pm 2 \mu \mathrm{m}$ \\
\hline Size of transformed Beta grain & $\sim 400 \mu \mathrm{m}$ & $46 \pm 2 \mu \mathrm{m}$ & NA \\
\hline
\end{tabular}

\section{$\underline{\text { Uniaxial tensile testing }}$}

Uniaxial tensile tests as discussed in Section 2 were performed on the samples obtained from rods after the three different heat treatments. The engineering stress-strain curves are shown in Figure 6. The mechanical properties are summarized in Table 2. It can be seen that the bimodal microstructure shows higher yield and ultimate tensile strength and also highest ductility. While 
fully lamellar microstructure has higher strength than the fully equiaxed microstructure, ductility is much lower than both equiaxed and bimodal microstructure. Fully equiaxed microstructure has a lower strength but similar ductility as that of bimodal.

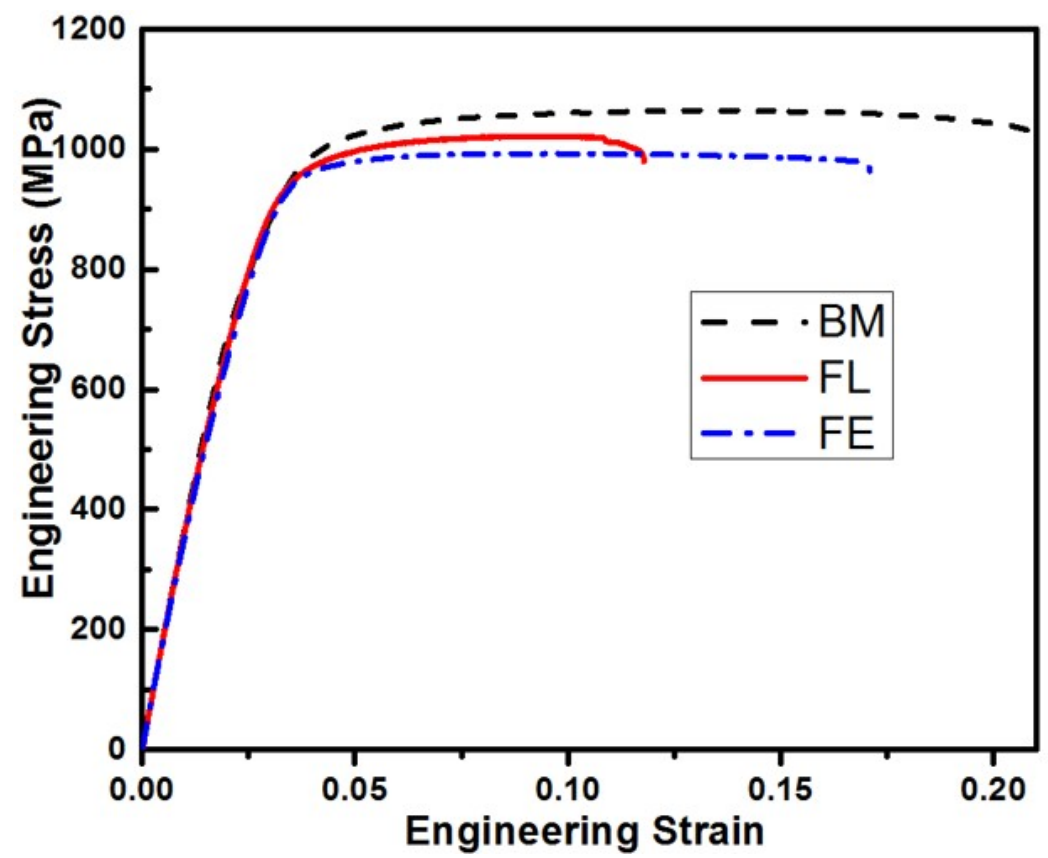

Fig. 6 Uniaxial tensile response of the 3 different microstructures investigated

Table 2 Uniaxial tensile properties

\begin{tabular}{|c|c|c|c|}
\hline & $0.2 \%$ б (MPa) & UTS (MPa) & \% Elongation \\
\hline FL & $918 \pm 20$ & $1028 \pm 20$ & $12 \pm 0.5$ \\
\hline BM & $930 \pm 5$ & $1066 \pm 5$ & $19 \pm 2$ \\
\hline FE & $893 \pm 15$ & $983 \pm 15$ & $18 \pm 1$ \\
\hline
\end{tabular}

$\underline{\text { Fatigue test results }}$

The $0.2 \%$ yield strength obtained from the uniaxial tensile tests was used to calculate the load levels for fatigue testing. The strain evolution with number of cycles for all 3 microstructures is shown in Fig. 7. It can be seen that the plastic strain accumulation is much higher under dwell fatigue loading condition when compared to normal fatigue. In case of normal fatigue, a very small amount of strain is accumulated prior to fracture. This accumulation of strain is simply due to the unsymmetrical 
stress-controlled loading and is called ratchetting in general. But in case of dwell fatigue the total strain accumulated prior to rupture is very high. This arises mainly due to the propensity of alpha phase to undergo creep deformation during the hold period. The number of cycles to failure in normal and dwell fatigue for all three microstructures is given in Table 3 . It can be seen from Table 3 that all the three microstructures suffer at least about an order of magnitude reduction in life as shown by the debit values. Surprisingly, the bimodal microstructure suffers the highest dwell fatigue debit. The normal fatigue life is highest for bimodal sample, while the dwell fatigue life is the lowest. Fully lamellar microstructure has the lowest normal fatigue life, while the dwell fatigue life is better than bimodal. Fully equiaxed microstructure has the highest dwell fatigue life and intermediate normal fatigue life. So, this microstructure has the optimum combination of normal and dwell fatigue resistance. The lower dwell fatigue life of bimodal microstructures despite their higher monotonic ductility is worth further investigation. The formation and propagation of short fatigue cracks and their dependence on the microstructural features might be responsible for the difference in dwell fatigue lives. Detailed fractographic and EBSD of the fractured samples are necessary to explain these results and will be the focus of future studies. 

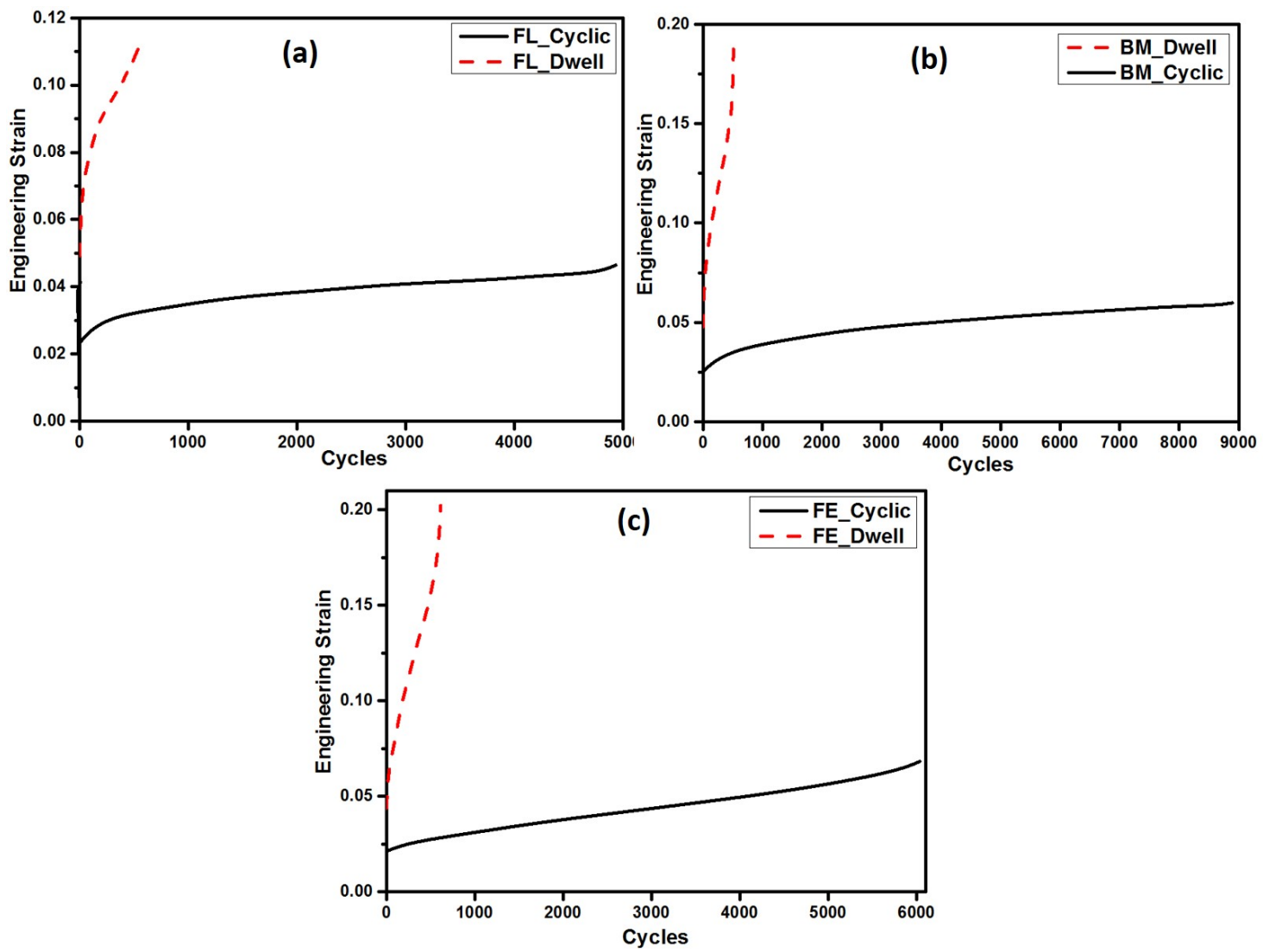

Fig. 7 Strain accumulation with number of cycles under fatigue and dwell fatigue loading for (a) fully lamellar (b) bimodal and (c) fully equiaxed microstructures

Table 3 Normal and dwell fatigue test results

\begin{tabular}{||c||c||c|c|}
\hline & Cyclic & Dwell & Debit \\
\hline \hline BM & 8894 & 511 & 17 \\
\hline \hline FL & 4934 & 550 & 9 \\
\hline \hline FE & 6004 & 602 & 10 \\
\hline \hline
\end{tabular}

\section{Conclusions}

Dwell fatigue behavior of IMI 834 alloy under three different microstructures was investigated. The salient outcomes of this work are as follows. 
1. The imposition of a dwell time leads to at least an order of magnitude reduction in fatigue life of IMI 834 irrespective of the microstructural condition.

2. The reduction in fatigue life is due to the high plastic strain accumulation during the dwell period.

3. Fully equiaxed microstructure shows an optimum combination of normal and dwell fatigue life.

\section{Acknowledgement}

The authors would like to acknowledge Prof. Dipankar Banerjee, Dept. of Materials Engineering IISc, Bangalore, India, for his encouragement to carry out this work. The authors would like to acknowledge Prof. Nilesh Gurao for the fatigue and dwell fatigue testing facility at the Microstructure, Texture and Stress Laboratory, Dept. of Materials Science and Engineering, IIT Kanpur, India. We are also thankful to the Department of Science and Technology (DST), India for financial support.

\section{References:}

[1] M.R. Bache, A review of dwell sensitive fatigue in titanium alloys: the role of microstructure , texture and operating conditions, Int. J. Fatigue. 25 (2003) 1079-1087. doi:10.1016/S0142-1123(03)00145-2.

[2] M.R. Bache, W.J. Evans, H.M. Davies, Electron back scattered diffraction (EBSD) analysis of quasi-cleavage and hydrogen induced fractures under cyclic and dwell loading in titanium alloys, J. Mater. Sci. (1997). doi:10.1023/A:1018624801310.

[3] W.J. Evans, Optimising mechanical properties in alpha + beta titanium alloys, Mater. Sci. Eng. A. 243 (1998) 89-96.

[4] Z. Zhang, M.A. Cuddihy, F.P.E. Dunne, On rate-dependent polycrystal deformation: the temperature sensitivity of cold dwell fatigue, Proc. R. Soc. A Math. Phys. Eng. Sci. 471 (2015) 20150214. doi:10.1098/rspa.2015.0214.

[5] T. Neeraj, D.H. Hou, G.S. Daehn, M.J. Mills, Phenomenological and microstructural analysis of room temperature creep in titanium alloys, Acta Mater. 48 (2000) 1225-1238. doi:10.1016/S1359-6454(99)00426-7.

[6] A.L. Pilchak, A. Hutson, W.J. Porter, D. Buchanan, R. John, On the Cyclic Fatigue and Dwell Fatigue Crack Growth Response of Ti-6Al-4V, Proc. 13th World Conf. Titan. (2016) 993-998. doi:10.1002/9781119296126.ch169.

[7] V. Sinha, M.J. Mills, J.C. Williams, Crystallography of Fracture Facets in a Near-Alpha Titanium Alloy, Metall. Mater. Trans. A. 37 (2015).

[8] V. Hasija, S. Ghosh, M.J. Mills, D.S. Joseph, Deformation and creep modeling in polycrystalline Ti-6Al alloys, Acta Mater. 51 (2003) 4533-4549. doi:10.1016/S1359-6454(03)00289-1.

[9] F.P.E. Dunne, A. Walker, D. Rugg, A systematic study of hcp crystal orientation and morphology effects in polycrystal deformation and fatigue, Proc. R. Soc. A. (2007) 1467-1489. doi:10.1098/rspa.2007.1833.

[10] V. Sinha, J.E. Spowart, M.J. Mills, J.C. Williams, Observations on the Faceted Initiation Site in the Dwell-Fatigue Tested Ti-6242 Alloy: Crystallographic Orientation and Size Effects, Metall. Mater. Trans. A. 37 (2006) 1507-1518. 
[11] U.. N.Gey, P.Bocher, M.Humbert, J.Jilbert, Texture heterogeneities in $\alpha \mathrm{p} / \alpha \mathrm{s}$ titanium forging analysed by EBSDRelation to fatigue crack propagation, J. Microsc. 233 (2009) 451-459.

[12] Z. Zheng, A. Stapleton, K. Fox, F.P.E. Dunne, Understanding thermal alleviation in cold dwell fatigue in titanium alloys, Int. J. Plast. (2018) 0-1. doi:10.1016/j.ijplas.2018.07.018.

[13] V. Chandravanshi, K. Prasad, V. Singh, A. Bhattacharjee, V. Kumar, Effects of a $+b$ phase deformation on microstructure, fatigue and dwell fatigue behavior of a near-alpha titanium alloy, 91 (2016) $100-109$. doi:10.1016/j.ijfatigue.2016.05.023. 